\title{
Analyses on K-ras mutations and fascin expression in patients with cardia cancer
}

\author{
LI WEI ${ }^{*}$, HAIYAN CHANG ${ }^{2 *}$ and SONG HUO ${ }^{3}$ \\ Departments of ${ }^{1}$ Pathology and ${ }^{2}$ Gastrointestinal Surgery, Jining First People's Hospital, Jining, Shandong 272111; \\ ${ }^{3}$ Department of Pathology, Jining Tumor Hospital, Jining, Shandong 272000, P.R. China
}

Received April 27, 2018; Accepted November 2, 2018

DOI: 10.3892/ol.2018.9750

\begin{abstract}
Mutations of K-rat sarcoma (K-ras) in patients with cardia cancer and their effects on the expression of fascin were investigated. A total of 90 cardia cancer patients treated in Jining First People's Hospital from March 2014 to March 2017 were randomly selected. Genomic deoxyribonucleic acid (DNA) was extracted from paraffin-embedded cardia cancer specimens. Pyrosequencing was applied to detect sequences of K-ras gene in all patients and to analyze the mutations of K-ras gene. Then, genotyping of mutations at each mutation site was carried out using quantitative polymerase chain reaction (qPCR). The expression level of fascin in patients was measured via immunohistochemistry and qPCR. The results revealed that among 90 patients with cardia cancer, 21 patients had K-ras mutations (23.3\%), including 20 cases of exon 12 mutation and 1 case of exon 13 mutation. Risk factor analyses revealed that alcohol abuse was a high risk factor for mutations $(\mathrm{p}<0.05)$. There was no significant difference in the mutation probability between heterozygotes and homozygotes for four mutations at codon 12 ( $\mathrm{p}>0.05)$. The heterozygote at codon 13 had a higher mutation probability than homozygote $(p<0.05)$. Immunohistochemistry suggested that the number of positive cells in the mutant group was larger than that in the non-mutant group $(\mathrm{p}<0.05)$. The results of qPCR showed that the expression level of fascin gene in the mutant group was 2.3 times higher than that in the non-mutant group $(\mathrm{p}<0.05)$. In conclusion, the probability of codon 12 mutation in K-ras gene is increased in patients with cardia cancer, and fascin is highly expressed in mutant patients, which is positively correlated with the mutations in K-ras gene.
\end{abstract}

Correspondence to: Dr Song Huo, Department of Pathology, Jining Tumor Hospital, 67 Jianshebei Road, Jining, Shandong 272000, P.R. China

E-mail: houq16@126.com

*Contributed equally

Key words: cardia cancer, K-rat sarcoma, mutation, fascin

\section{Introduction}

Cardia cancer is a malignant digestive system tumor occurring at the cardia, which is also one of the major tumors in middle-aged and elderly people, frequently occurring in people aged $>40$ years and accounting for $\sim 1 / 10$ of digestive system tumors $(1,2)$. Its mortality rate is decreasing year by year with the improvement in diagnosis and treatment, but the therapeutic effect is not ideal, and a considerable proportion of conditions still cannot be controlled, leading to the deterioration of cardia cancer cells and poor efficacy of radiochemotherapy, so that patients are not treated and cured. Cardia cancer is deemed to be caused by many factors, among which genetic factor is considered to be the chief culprit in addition to unhealthy diet and environmental factor. Changes in gene structure result in changes in protein levels $(3,4)$. Gene polymorphism indicates that the base structure and quantity of the same gene in different populations are different, which will lead to changes in the level of translation, thereby affecting the physical growth and metabolic function relating to such a gene (5). Currently, mutations in K-rat sarcoma (K-ras) gene are considered to be the major cause of malignant tumors. $\mathrm{K}$-ras, as a member of the ras gene family, encodes the K-ras protein, which is correlated with tumor formation, proliferation, migration, diffusion and angiogenesis. Numerous studies have confirmed that K-ras may be involved in regulating multiple signaling pathways, and uncontrolled cell proliferation represents a tendency of tumor development (6). Fascin protein is highly expressed in many tumor tissues and plays an important role in the proliferation, invasion and metastasis of tumors, which is an independent factor in the prognosis of many tumors $(7,8)$. There are rare studies on the correlation of cardia cancer with K-ras mutations and fascin expression up to now. Therefore, this study linked K-ras gene mutations and fascin expression with cardia cancer and explored the relationship of cardia cancer with pathogenic genes from a genetic perspective.

\section{Materials and methods}

General data. A total of 90 cardia cancer patients (average age $58.34 \pm 12.01$ years and medially weighing $67.23 \pm 12.34 \mathrm{~kg}$ ) treated in Jining First People's Hospital (Jining, China) from March 2014 to March 2017 were enrolled, including 56 males 
Table I. Primer sequences of fluorescence quantitative PCR.

\begin{tabular}{lrr}
\hline \multicolumn{1}{c}{ Primer sequences } & \multicolumn{1}{c}{ Probe sequences } \\
\hline K-ras & F: 5'-TTCAAGCCCTCAGTCAGTTG-3' & FAM: 5'-GGAGCTGGTGGCGTAGG-3' \\
& R: 5'-CACCGTCTCCAGTCAGCAGCTG-3' & VIC: 5 '-GGAGCTGATGGCGTAGG-3'(12,35G>A) \\
& 5'-GGAGCTGTTGGCGTAGG-3'(12,35G $>$ T) \\
& 5'-GGAGCTGCTGGCGTAGG-3'(12,35G>C) \\
& 5'-GGAGCTCGTGGCGTAGG-3'(12,34G>C) \\
& 5'-GGAGCTGGTGACGTAGG-3'(13,35G>C)
\end{tabular}

Fascin F: 5'-CCTGGACHCCAACCGCTCC-3'

FAM: 5'-GACGGTGGGCAGTGACTCCG-3' R: 5'-CCACAGGAGTGTCGCCGCTG-3'

qPCR, quantitative polymerase chain reaction; K-ras, K-rat sarcoma; F, forward; R, reverse.

and 34 females. Based on pathological staging, 24 patients had stage $\mathrm{T}_{\text {is }}$ tumor, 43 patients had stage T1-T2 tumor, and 13 patients had stage T3-T4 tumor. All the patients were informed and signed the informed consent. This study was approved by the Ethics Committee of Jining First People's Hospital.

Extraction of genomic deoxyribonucleic acid (DNA). Paraffin-embedded cardia specimens were collected from all patients, from whom genomic DNA was extracted using a genomic extraction reagent (Qiagen, Inc., Valencia, CA, USA). The concentration and purity of DNA were determined using a NanoDrop, and DNA was stored at $-20^{\circ} \mathrm{C}$.

Sequencing of K-ras gene. K-ras gene was subjected to quantitative polymerase chain reaction (qPCR) amplification and purification and then sequenced on an automated gene analyzer (ABI3130XL). The results were analyzed using the sequencing analysis software Chromas.

Single-nucleotide polymorphism (SNP) typing of K-ras gene and detection of relative expression of fascin gene through $q P C R$. Primer sequences and their TaqMan probe sequences at SNP site were designed by Oligo 6.0 (Table II). Primers were synthesized by Sangon Biotech Co., Ltd. (Shanghai, China) (Table I). Reaction was performed using a qPCR instrument under the following conditions: i) 1 cycle of $94^{\circ} \mathrm{C}$ for $3 \mathrm{~min}$; and ii) 42 cycles of $94^{\circ} \mathrm{C}$ for $15 \mathrm{sec}$ and $60^{\circ} \mathrm{C}$ for $60 \mathrm{sec}$. After each cycle, the fluorescence value was read. The experimental results were generated by the built-in software of the instrument. Each sample was tested in triplicate. GAPDH was used as a negative control. A positive plasmid containing such a sequence (synthesized by Sangon Biotech Co., Ltd.) was employed as a positive control. The cycle threshold $(\mathrm{Cq})$ value was output from the instrument, and experimental results were analyzed using the $2^{-\Delta \Delta C q}$ method (9).

Detection of fascin expression in cardia cancer cells via immunohistochemistry. Specimens were fixed with $10 \%$ formaldehyde at $20^{\circ} \mathrm{C}$ for $16 \mathrm{~h}$. Selected paraffin-embedded specimens were cut into sections with $4 \mu \mathrm{m}$ in thickness. Then, the sections were stained using immunohistochemistry MaxVision two-step method blocked with $5 \%$ milk at $20^{\circ} \mathrm{C}$
Table II. K-ras mutations in patients with cardia cancer.

\begin{tabular}{lllll}
\hline Codon & $\begin{array}{c}\text { Type of } \\
\text { mutation }\end{array}$ & $\begin{array}{c}\text { Amino acid } \\
\text { change }\end{array}$ & Case & Rate \\
\hline 12 & $35 \mathrm{G}>\mathrm{A}$ & $\mathrm{Gly} \rightarrow$ Asp & 7 & 33.3 \\
& $35 \mathrm{G}>\mathrm{T}$ & $\mathrm{Gly} \rightarrow$ Val & 5 & 23.8 \\
& $35 \mathrm{G}>\mathrm{C}$ & $\mathrm{Gly} \rightarrow$ Cys & 5 & 23.8 \\
& $34 \mathrm{G}>\mathrm{A}$ & $\mathrm{Gly} \rightarrow$ Ser & 3 & 14.3 \\
& $34 \mathrm{G}>\mathrm{A}$ & $\mathrm{Gly} \rightarrow$ Asp & 1 & 4.8 \\
\hline
\end{tabular}

K-ras, K-rat sarcoma.

for $2 \mathrm{~h}$. After that, mouse anti-human fascin monoclonal antibodies (dilution, 1:200; MAB-0228, clone no. FCN01) and MaxVision immunohistochemistry kits (both from Fuzhou Maxim Biotech, Inc., Fuzhou, China) were used. Fascin was expressed in normal vascular endothelial cells and was used as a positive control. Phosphate-buffered saline (PBS) was used as a negative control instead of primary antibody. For each section, a total of five representative high-power fields (x400) were selected for observation.

Statistical analysis. Statistical Product and Service Solutions (SPSS) 17.0 software package (SPSS, Inc., Chicago, IL, USA) was adopted for statistical analyses. Measurement data were expressed as means $\pm \mathrm{SD}$, and t-test was used. Enumeration data were expressed as $\%$, and $\chi^{2}$ test was applied. $\mathrm{P}<0.05$ indicated that the difference was statistically significant.

\section{Results}

K-ras mutations in patients with cardia cancer. A total of 21 out of 90 patients with cardia cancer had mutations in K-ras gene, accounting for $23.3 \%$ of mutant patients. Among these 21 patients, 20 patients had exon 12 mutation, accounting for $95.2 \%$, and the mutations were mainly detected in $35 \mathrm{G}>\mathrm{A}$, $35 \mathrm{G}>\mathrm{T}, 35 \mathrm{G}>\mathrm{C}, 34 \mathrm{G}>\mathrm{A}$ and $34 \mathrm{G}>\mathrm{T}$. One patient had exon 13 mutation, namely mutation $38 \mathrm{G}>\mathrm{A}$, accounting for $4.8 \%$ of mutant patients (Table II). 
Table III. Correlation analyses on risk factors for K-ras mutations.

\begin{tabular}{|c|c|c|c|c|c|c|c|c|}
\hline \multirow[b]{2}{*}{ Groups } & \multirow[b]{2}{*}{ Case (n) } & \multirow[b]{2}{*}{ Age (years) } & \multirow{2}{*}{$\begin{array}{c}\text { Sex } \\
(\text { male/female, \%) }\end{array}$} & \multirow[b]{2}{*}{ Weight $(\mathrm{kg})$} & \multicolumn{3}{|c|}{ Pathological stage (\%) } & \multirow{2}{*}{$\begin{array}{c}\text { Alcohol } \\
\text { abuse (\%) }\end{array}$} \\
\hline & & & & & $\mathrm{T}_{\mathrm{is}}$ & $\mathrm{T} 1-\mathrm{T} 2$ & $\mathrm{~T} 3-\mathrm{T} 4$ & \\
\hline Mutant & 21 & $57.21 \pm 11.21$ & 53.2 & $68.23 \pm 13.52$ & 18 & 68 & 14 & 45 \\
\hline Non-mutant & 69 & $59.45 \pm 12.62$ & 52.4 & $65.41 \pm 12.68$ & 16 & 67 & 17 & 12 \\
\hline$\chi^{2} / t$ & - & 2.435 & 0.013 & 4.123 & & 0.415 & & 26.721 \\
\hline P-value & - & 0.675 & 0.909 & 0.371 & & 0.813 & & $<0.001$ \\
\hline
\end{tabular}

K-ras, K-rat sarcoma.

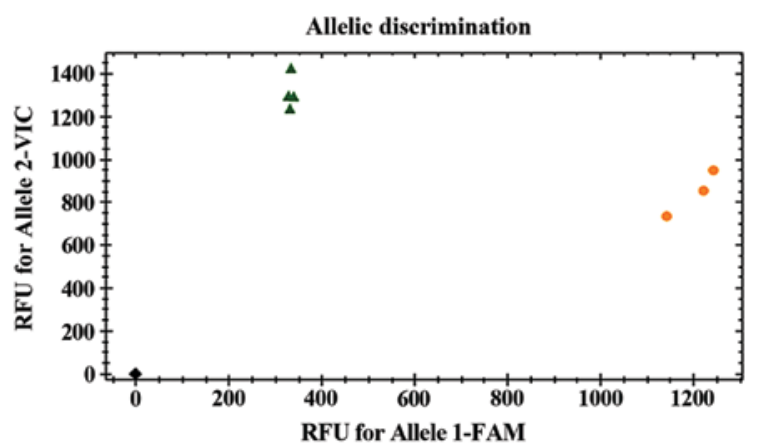

Figure 1. qPCR genotyping results of $35 \mathrm{G}>\mathrm{A}$ at codon 12. qPCR, quantitative polymerase chain reaction.

Pearson's correlation analysis on risk factors for $K$-ras mutations in cardia cancer. There were no statistically significant differences in age, sex, weight and pathological stage between the 21 patients with mutations and those without mutations ( $p>0.05)$, but the mutation probability in patients with alcohol abuse was higher than that in those without alcohol abuse, showing a statistically significant difference $(\mathrm{p}<0.05)$ (Table III).

Distribution of mutant genotypes in K-ras in cardia cancer. The genotypes containing mutant bases at each mutation site were distributed as shown in Fig. 1. The difference in the mutation probability between heterozygotes and homozygotes for four codon 12 mutations was not significant $(\mathrm{p}>0.05)$, but for one codon 13 mutation, the mutation probability of heterozygotes was higher than that of homozygotes $(\mathrm{p}<0.05)$ (Table IV).

Comparison of fascin expression between mutant and non-mutant groups. The expression level of fascin was compared between the mutant and non-mutant groups at the molecular and protein levels, respectively. Immunohistochemistry revealed that the number of positive cells in the mutant group was increased compared with that in the non-mutant group $(\mathrm{p}<0.05)$ (Fig. 2). qPCR results showed that the expression level of fascin gene in the mutant group was 2.3 times higher than that in the non-mutant group (Fig. 3).

\section{Discussion}

It has been reported that pathogenic factors for cardia cancer are various, including diet, microbiota in the body and external
Table IV. Distribution of mutant genotypes in K-ras in cardia cancer $(\mathrm{n}, \%)$.

\begin{tabular}{|c|c|c|c|c|c|}
\hline Codon & $\begin{array}{l}\text { Type of } \\
\text { mutation }\end{array}$ & Genotype & Case $(\%)$ & $\chi^{2}$ & $\mathrm{P}$-value \\
\hline \multirow[t]{8}{*}{12} & \multirow[t]{2}{*}{$35 \mathrm{G}>\mathrm{A}$} & GA & 4 (19) & \multirow[t]{2}{*}{0.796} & \multirow[t]{2}{*}{0.372} \\
\hline & & $\mathrm{AA}$ & 3 (14.3) & & \\
\hline & \multirow[t]{2}{*}{$35 \mathrm{G}>\mathrm{T}$} & GT & $3(14.3)$ & \multirow[t]{2}{*}{1.099} & \multirow[t]{2}{*}{0.294} \\
\hline & & TT & $2(9.5)$ & & \\
\hline & \multirow[t]{2}{*}{$35 \mathrm{G}>\mathrm{C}$} & $\mathrm{GC}$ & $3(14.3)$ & \multirow[t]{2}{*}{1.099} & \multirow[t]{2}{*}{0.294} \\
\hline & & $\mathrm{CC}$ & $2(9.5)$ & & \\
\hline & \multirow[t]{2}{*}{$34 \mathrm{G}>\mathrm{A}$} & GA & $2(9.5)$ & \multirow[t]{2}{*}{1.664} & \multirow[t]{2}{*}{0.197} \\
\hline & & $\mathrm{AA}$ & $1(4.8)$ & & \\
\hline \multirow[t]{2}{*}{13} & \multirow[t]{2}{*}{$34 \mathrm{G}>\mathrm{A}$} & GA & $1(4.8)$ & \multirow[t]{2}{*}{4.918} & \multirow[t]{2}{*}{0.027} \\
\hline & & AA & $0(0)$ & & \\
\hline
\end{tabular}

K-ras, K-rat sarcoma.

environmental stimuli. Studies on genetic inheritance are rare, but with the development of sequencing and PCR technologies, more and more attention is paid to the research on the influence of genetic inheritance on cancers $(10,11)$. K-ras gene, as a member of ras gene, is now a hotspot gene in the research on gastrointestinal tumors. Moreover, it has the greatest impact on human cancers as a molecular switch, i.e., when it is normal, it can control and regulate the path of cell growth, while it leads to continuous grow and prevents self-destruction of cells in case of abnormality (12). In addition, K-ras is involved in intracellular signal transduction. When K-ras gene is mutated, it is permanently activated and cannot produce normal ras proteins, resulting in disordered intracellular signal transduction and uncontrolled cell proliferation, thus leading to carcinogenesis (13). At present, there are some studies on K-ras gene in colorectal, gastric and pancreatic cancer (14-16). A study by Stewart and Crook (17) found that K-ras gene mutations are frequently detected in female patients with colorectal cancer and lymph node metastasis, which are expected to be important indicators determining the prognosis of colorectal cancer. Lee et al (18) pointed out in a study on gastric cancer that the probability of K-ras mutations in distant metastasis group is higher than that in the non-distant metastasis group. The expression function of the gene can be affected by many 

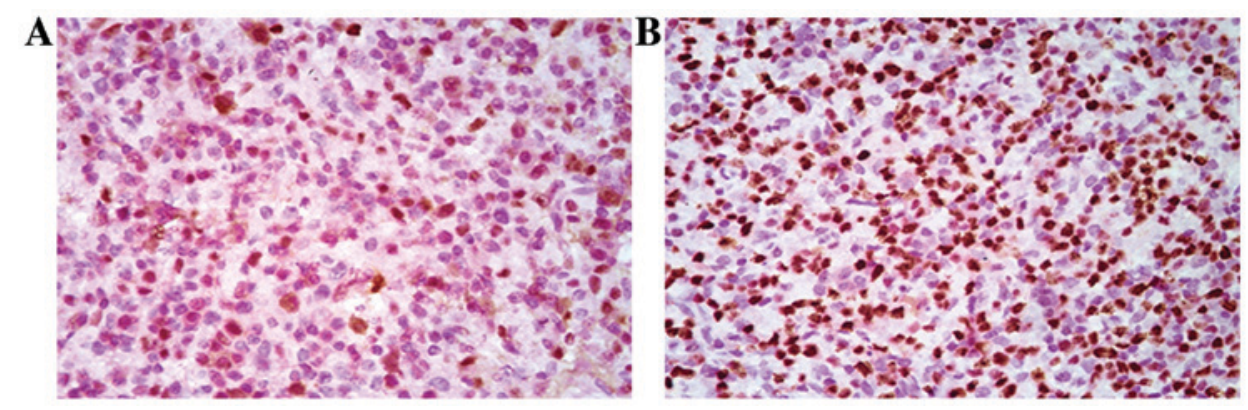

Figure 2. Results of immunohistochemistry for fascin in cardia cancer ( $\mathrm{p}<0.05)$. Results of immunohistochemistry in (A) the non-mutant and (B) mutant groups. The number of positive cells in the mutant group is greater than that in the non-mutant group $(\mathrm{p}<0.05)$.

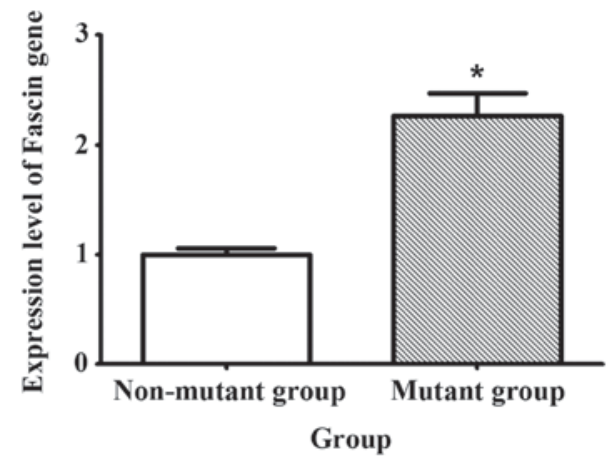

Figure 3. Results of qPCR. The expression level of fascin gene in the mutant group is higher than that in the non-mutant group. qPCR, quantitative polymerase chain reaction. ${ }^{*} \mathrm{p}<0.05$, compared with the non-mutant group.

factors including the roles of non-coding regions and various regulatory factors. Spontaneous SNPs of the gene change the structure, affect the realization of translation function and indirectly influence the health of the body, thus resulting in various diseases (19). This study proved that the probability of K-ras mutations in patients with cardia cancer was $23.3 \%$. Most mutations occurred at codon 12 , but there was no significant difference in the mutation probability between heterozygotes and homozygotes for four mutations at codon 12 . The mutation probability of heterozygotes at codon 13 was higher than that of homozygotes at codon 13 , but the number of cases was small. Therefore, the sample size should be increased for further confirmation.

Fascin is able to reduce the matrix resistance between cells to promote cell migration, thus facilitating the infiltration and metastasis of tumor cells. Fascin exists in three forms in the human body, namely, fascin-1, -2 and -3 . Among them, fascin-1 is the dominant. A study suggested that fascin is often lowly expressed when the body is in normal condition, but the expression of fascin is increased in tumor cells (20). A study of Omran and Al Sheeha (21) discovered that the expression level of fascin is diverse in different tumors. Studies have indicated that fascin expression in gastric cancer tissue is significantly higher than that in normal gastric mucosa and is related to lymph node and distant metastasis in gastric cancer. In this study, immunohistochemistry revealed that the number of positive cells in the mutant group was greater than that in the non-mutant group, and the results of qPCR showed that the expression level of fascin gene in the mutant group was 2.3 times higher than that in the non-mutant group, indicating that the expression of fascin is still high in cardia cancer cells and is positively correlated with K-ras gene mutations.

In summary, the mutation probability of codon 12 is high in K-ras gene in patients with cardia cancer, and the expression of fascin is high in mutant patients and positively related to the mutations in K-ras gene.

\section{Acknowledgements}

Not applicable.

\section{Funding}

No funding was received.

\section{Availability of data and materials}

The datasets used and/or analyzed during the current study are available from the corresponding author on reasonable request.

\section{Authors' contributions}

LW wrote the manuscript. LW and HC helped with the extraction of genomic DNA and qPCR. SH was responsible for immunohistochemistry. All authors read and approved the final manuscript.

\section{Ethics approval and consent to participate}

The study was approved by the Ethics Committee of Jining First People's Hospital (Jining, China) and informed consents were signed by the patients or guardians.

\section{Patient consent for publication}

Not applicable.

\section{Competing interests}

The authors declare that they have no competing interests.

\section{References}

1. Chen Y, Kang Y, Hong L and Yao H: Hypoglycemia caused by co-secretion of insulin from lung tumor and cardia cancer: First case report. Sao Paulo Med J: Nov 17, 2017 (Epub ahead of print). 
2. Guo W, Lv P, Liu S, Xu F, Guo Y, Shen S, Liang J, Kuang G and Dong Z: Aberrant methylation-mediated downregulation of long noncoding RNA C5orf66-AS1 promotes the development of gastric cardia adenocarcinoma. Mol Carcinog: Mar 22, 2018 (Epub ahead of print]).

3. Barra WF, Moreira FC, Pereira Cruz AM, Khayat AS, Calcagno DQ, Carneiro Dos Santos NP, Mascarenhas Junior RW, Thomaz Araújo TM, Ishak G, Demachki S, et al: GEJ cancers: Gastric or esophageal tumors? searching for the answer according to molecular identity. Oncotarget 8: 104286-104294, 2017.

4. Binh TT, Tuan VP, Dung HDQ, Tung PH, Tri TD, Thuan NPM, Khien VV, Hoan PQ, Suzuki R, Uchida T, et al: Advanced non-cardia gastric cancer and Helicobacter pylori infection in Vietnam. Gut Pathog 9: 46, 2017.

5. Roviello F, Polom K, D'Ignazio A, Pascale V and Marrelli D: K-RAS mutation in gastric cancer and its link with microsatellite instability status. Eur J Cancer 92 (Suppl 2): S6, 2018.

6. Sekita-Hatakeyama Y, Nishikawa T, Takeuchi M, Morita K, Takeda M, Hatakeyama K, Nakai T, Uchiyama T, Itami H, Fujii T, et al: K-ras mutation analysis of residual liquid-based cytology specimens from endoscopic ultrasound-guided fine needle aspiration improves cell block diagnosis of pancreatic ductal adenocarcinoma. PLoS One 13: e0193692, 2018.

7. Lin YJ and Haigis KM: Brother's keeper: Wild-type mutant K-ras dimers limit oncogenesis. Cell 172: 645-647, 2018.

8. Jimbo K, Yokoyama K, Ogawa M, Hirano M, Ochi K, Kobayashi M, Yusa N, Shimizu E, Kawamata T, Yasui H, et al: Autologous peripheral blood stem cell transplantation for double-refractory myeloma with K-RAS and N-RAS mutations. Rinsho Ketsueki 58: 2380-2385, 2017 (In Japanese).

9. Livak KJ and Schmittgen TD: Analysis of relative gene expression data using real-time quantitative PCR and the 2(-Delta Delta C(T)) method. Methods 25: 402-408, 2001.

10. Siddiqui I, Erreni M, Kamal MA, Porta C, Marchesi F, Pesce S, Pasqualini F, Schiarea S, Chiabrando C, Mantovani A, et al: Differential role of Interleukin-1 and Interleukin-6 in $\mathrm{K}$-Ras-driven pancreatic carcinoma undergoing mesenchymal transition. OncoImmunology 7: e1388485, 2017.

11. Wang X, Wang J, Chen F, Zhong Z and Qi L: Detection of K-ras gene mutations in feces by magnetic nanoprobe in patients with pancreatic cancer: A preliminary study. Exp Ther Med 15 527-531, 2018.

12. Zhou Y and Hancock JF: A novel prenyl-polybasic domain code determines lipid-binding specificity of the K-Ras membrane anchor. Small GTPases 15: 1-5, 2018.
13. Son BK, Kim DH, Min KW, Kim EK and Kwon MJ: Smad4/Fascin index is highly prognostic in patients with diffuse type EBV-associated gastric cancer. Pathol Res Pract 214: 475-481, 2018.

14. Koçer NE and Kayaselçuk F: Is availability of anti-EGFR therapy for the colorectal adenocarcinomas showing fascin expression limited? Target Oncol 9: 171-175, 2014.

15. Wang MT, Holderfield M, Galeas J, Delrosario R, To MD, Balmain A and McCormick F: K-Ras promotes tumorigenicity through suppression of non-canonical Wnt signaling. Cell 163: $1237-1251,2015$

16. Xu W, Wang Z, Zhang W, Qian K, Li H, Kong D, Li Y and Tang Y: Mutated K-ras activates CDK8 to stimulate the epithelial-to-mesenchymal transition in pancreatic cancer in part via the Wnt/ $\beta$-catenin signaling pathway. Cancer Lett 356 (2 Pt B): 613-627, 2015.

17. Stewart CJ and Crook ML: Fascin expression in undifferentiated and dedifferentiated endometrial carcinoma. Hum Pathol 46: 1514-1520, 2015

18. Lee LY, Chen YJ, Lu YC, Liao CT, Chen IH, Chang JT, Huang YC, Chen WH, Huang CC, Tsai CY, et al: Fascin is a circulating tumor marker for head and neck cancer as determined by a proteomic analysis of interstitial fluid from the tumor microenvironment. Clin Chem Lab Med 53: 1631-1641, 2015.

19. Zhao W, Gao J, Wu J, Liu QH, Wang ZG, Li HL and Xing LH: Expression of Fascin-1 on human lung cancer and paracarcinoma tissue and its relation to clinicopathological characteristics in patients with lung cancer. Onco Targets Ther 8: 2571-2576, 2015.

20. Abrams JA, Gonsalves L and Neugut AI: Diverging trends in the incidence of reflux-related and Helicobacter pylori-related gastric cardia cancer. J Clin Gastroenterol 47: 322-327, 2013.

21. Omran OM and Al Sheeha M: Cytoskeletal focal adhesion proteins fascin-1 and paxillin are predictors of malignant progression and poor prognosis in human breast cancer. $\mathrm{J}$ Environ Pathol Toxicol Oncol 34: 201-212, 2015.

This work is licensed under a Creative Commons Attribution-NonCommercial-NoDerivatives 4.0 International (CC BY-NC-ND 4.0) License. 